\title{
NO'TAS
}

\section{ESPACIO, TIEMPO Y GÉNERO EN LA DOROTEA}

Un examen cuidadoso de la Dorotea nos manifiesta el gran empeño que puso Lope en fincar la obra en condiciones realistas de tiempo y espacio. El lector ve cómo, pese a la estilización literaria que ellos mismos se imponen, los personajes siguen ligados a un mundo semejante al nuestro. Deliberadamente, Lope les ha negado un privilegio otorgado a las figuras de sus comedias: el de pasearse por la tierra a su antojo, el de hacer tajos caprichosos en los años de sus vidas. La libertad del "más libre teatro" - y esto es la Dorotea, según su autor- es sólo un emanciparse de las exigencias de público y representantes ("No se ven las personas vestidas, sino las acciones imitadas", afirma el prólogo). Lo paradójico es que Lope se ha servido de esta libertad para atarse mucho más que nunca a las condiciones realistas de tiempo y espacio. ¿Con qué objeto? La busca de una respuesta a esta pregunta arrojará, según espero, algunas luces sobre la forma interior y el significado de la Dorotea.

Observemos bien, ante todo, de qué manera se manejan los valores artísticos de espacio y tiempo en la "acción en prosa". Desde el comienzo, su estructura externa nos revela un contraste con la comedia: la división en cinco largos actos, subdivididos a su vez en escenas. Es evidente aquí la influencia de la Euphrosina: tales divisiones sirven para marcar pasos casi imperceptibles en la acción que se va desarrollando lentamente, en agudo contraste con el movimiento dinámico de la comedia. Y sin embargo, si comparamos la Dorotea con la Euphrosina y la Celestina, obras igualmente dramáticas pero irrepresentables, vemos que Lope no se acerca siquiera al grado en que un Fernando de Rojas se liberó de las limitaciones físicas del tablado. Dentro de un aucto, Rojas suele mudar la escena sin indicación exterior, siguiendo a los personajes en sus idas y venidas - procedimiento bastante natural en una novela, pero anormal en una obra de teatro.

Lope, en cambio ni un solo momento deja de ser artista dramático. Hay en su retina interior un escenario, aun cuando destine su obra a la simple lectura. La edición original no trae acotaciones teatrales, pero en cada escena Lope mantiene a los personajes en un punto dado, con entradas y salidas perfectamente claras, gracias a las cuales se reúnen ciertas figuras en determinados momentos para conseguir efectos dramáticos bien calculados. Además, no encontramos en la Dorotea esa sucesión vertiginosa, tan frecuente en la comedia, de escenas totalmente 
distintas por el sitio en que se desarrollan. Lope hace transcurrir la acción siempre en Madrid. Si el punto de la ciudad cambia entre dos escenas, invariablemente deja que pase tiempo para que los personajes se trasladen de un lugar a otro. Pero hay una interrelación de las secuencias de tiempo y espacio, y estas últimas pueden apreciarse mejor si se ven en función de las primeras.

Naturalmente, en el ámbito temporal de la Dorotea no existe esa ambigüedad que tantos comentarios ha provocado en el caso de la Celestina. Rojas, como observa Stephen Gilman', presenta a unos personajes que han pasado por más experiencias de lo que permitiría la ordenación cronológica de su obra. A causa de ello, la forma dramática exterior parece constreñir de manera antinatural un tipo de desarrollo psíquico más apropiado para la presentación narrativa. Lope, en cambio, hace que la experiencia del tiempo en sus personajes se ajuste muy fielmente a la cronología de los acontecimientos percibida por el lector, como si éste fuera espectador en un teatro. No hay, por supuesto, una equivalencia literal, ni tampoco cabe esperarla; lo que hallamos es una relación coherente y convincente. La obra abarca un lapso de varios meses, pero dentro de cada escena coexisten en el tiempo el mundo artístico y el del lector. Por otra parte, Lope pone un empeño extraordinario en dar cuenta de las andanzas de sus personajes durante todo el tiempo que dura cada acto. Nada hay de violento ni de borroso cuando los hace ir de un sitio a otro, sin que nosotros los veamos. Lejos de eso, mantiene un nota. ble engranaje cronológico, con frecuentes menciones expresas de la hora. El acto I, por ejemplo, dura desde las primeras horas de la mañana hasta las dos de la tarde. Después de levantarse, agitada por su pugna interior, Dorotea se dispone a ver a Fernando por última vez; tropieza al salir de casa. Aquí la deja Lope, para "enfocar" a Fernando y a su ayo Julio en una larga discusión que termina con la llegada de Dorotea, la cual tropieza de nuevo al entrar (este detalle recrea simbólicamente el doloroso recorrido desde su casa hasta la de su amante). Riñen Fernando y Dorotea, y ésta se retira. Tras un largo y desesperado discurso, Fernando decide, con mucho sentido práctico, sacarle dinero engañosamente a Marfisa para hacer un viaje a Sevilla. Ahora vemos a Marfisa conversando con su criada. A poco llegan Julio y Fernando, y en cierto momento oímos la exclamación de este último: "¡Válame Dios, y lo que ha passado por mí desde las nueue a las doze!" (fol. $\left.37 \mathrm{r}^{\circ}\right)^{2}$. Viene ahora una charla entre T'eodora y Gerarda, que termina con la llegada de Dorotea, a quien reprende su madre por volver a las dos de la tarde. Mientras tanto, Fernando y Julio, ya de viaje, pasan en sus caballos bajo la ventana de Dorotea.

Lope mantiene sin quiebras a lo largo de la obra su densa concatenación de minutos y horas (con dos excepciones: la semana intercalada dentro del acto III, y el hueco de una noche dentro del V). Además, los intervalos entre los actos cumplen la función de hacer plausibles las nuevas situaciones en relación con el calendario físico. El diálogo suele

1 "El tiempo y el género literario en la Celestina", $R F H, 7$ (1945), 150 ss.

2 Las indicaciones de folio se refieren a la edición facsímil de la princeps publicada por la Real Academia, Madrid, 1951. 
dar pistas claras para medir el tiempo transcurrido y enterar al lector de los cambios operados en la vida interior y exterior de los personajes. Tres meses pasan entre el acto I y el III - el acto II transcurre más o menos a medio camino-, unos cuantos días entre el III y el IV, y varios meses entre el IV y el V. Esta última laguna se cubre con el largo y detallado relato que hace Fernando a su amigo César de cómo ha ido desenamorándose de Dorotea, proceso iniciado en el acto IV y concluido ya en el V. De manera análoga, Lope llena el intervalo existente entre los actos I y III con los informes casi cotidianos que lleva Ludovico a Fernando acerca de la lenta convalescencia de Dorotea y su gradual aceptación de don Bela como amante. En la primera escena del acto IV, el propio Fernando hace a Dorotea (que lo escucha sin darse a conocer) un informe igualmente detallado de lo que ha hecho entre tanto. Sumados a las escenas que ocurren ante nuestros ojos, estos circunstanciados relatos cumplen el objeto de presentar el desenamoramiento de Fernando y Dorotea como un largo y lento proceso de desintegración, sujeto a una prosaica sucesión de trabajos y días.

¿Por qué esta obsesión del tiempo que va pasando, del espacio que va poniendo un cerco a la vida humana? La respuesta nos parece clara. Cuando hacia 1630 el casi septuagenario Lope preparaba su versión final de la Dorotea (1632), el temperamento y la casualidad se combinaron para avivar en él ese sentido de la evanescencia de las cosas que tan particularmente obsesionaba a la época barroca. La Dorotea es el balance final de un hombre que ha vivido en su plenitud cada instante, gozándolo con todas las partes de su ser, y que ahora ha llegado a percibir cuán impermanentes e insustanciales eran esos instantes en sí mismos y cómo, sumados unos a otros, han formado años y años, llevándolo hasta el borde de la eternidad. La reacción de Lope no es una retractación ni una renuncia; es simplemente un suspiro de nostalgia ante la transitoriedad de los sentimientos y placeres humanos, que da su nota característica al "desengaño" de la Dorotea. Los cimientos del tiempo físico eran esenciales para presentar el efecto de la fugacidad del tiempo como algo más que un fenómeno momentáneo. En la Dorotea, el verdadero conflicto es el de los personajes enfrentados a su consciencia de los límites temporales y espaciales de sus vidas; la acción consiste en hacer confluir con el tiempo cronológico el sentido lírico del tiempo que surge como reacción contra él.

Observemos algunos aspectos de este proceso. Es evidente, ante todo, el extraordinario sentido del tiempo que tienen los personajes. Su consciencia de estar atados al hic et nunc es siempre aguda, por mucho que se empeñen en huir a un mundo intemporal de arte o de amor. El tema tradicional del carpe diem adquiere una premiosa intensidad personal. Ya al comienzo de la obra oímos a personas ancianas que añoran la mocedad, y a jóvenes cuyo angustioso temor de envejecer no los deja en libertad para vivir despreocupadamente la vida. "Quando yo era moça leí en Garzilaso aquello de «En tanto que de rosa y azucena...»: ¿piensas que el tiempo duerme quando nosotros?", pregunta la octogenaria Gerarda (fol. $260 \mathrm{r}^{\circ}$ ). $\mathrm{Y}$ don Bela observa: "Como quita cada día tan poco, no se siente" (fol. $228 \mathrm{r}^{\circ}$ ). El tiempo experimentado como una dimensión del 
vivir, tal como lo ha experimentado Lope, engloba en estos casos el tema literario del tempus irreparabile fugit.

En el fondo de todos sus personajes ha inculcado Lope su propia consciencia de que el tiempo es el enemigo. Si el amor ha de acabar algún día en aborrecimiento - reflexiona Dorotea en el acto I, cuando se decide a hacer su fatal visita a Fernando-, ¿por qué no terminar con él de una vez? Fernando exclama dramáticamente: "[No] sufrirá mi alma que el tiempo saque della vna Dorotea tan hermosa y me la ponga tan fea..." (fol. $121 \mathrm{v}^{\circ}$ ). Pero no ha pasado una semana cuando le dice a Julio: "No me pareció que era Dorotea la que yo imaginaua ausente, no tan hermosa, no tan graciosa, no tan entendida..." (fol. $221 \mathrm{r}^{\circ}$ ). La aspiración misma a vivir en la atmósfera de la literatura es un intento de atajar el fluir del tiempo, de dar a la experiencia la permanencia del arte: "¿Qué mayor riqueza para vna muger que verse eternizada?", pregunta Dorotea (fol. $5^{2} \mathrm{v}^{0}$ ) cuando busca una liberación de su propia prosaica existencia en compañía de las heroínas del intemporal mundo pastoril.

Desde el comienzo sentimos que el amor de Fernando y Dorotea se ha pasado de maduro después de cinco años. Lope mantiene estilística* mente nuestra impresión aludiendo a este amor con imágenes visuales, olfativas, gustativas, que sugieren decadencia y descomposición físicas: cartas de amor echadas al fuego, en que se ven "letras quemadas, blancas entre lo negro del papel" (fol. $267 \mathrm{r}^{\circ}$ ); "Ya sabéis con qué olor dexan las flores el agua del vaso en que estuuieron" (fol. $54 \mathrm{r}^{\circ}$ ); "amores rancios como perniles..." (fol. $\left.257 \mathrm{r}^{\circ}\right)$. Estos toques orgánicos son característicos del sentido lopesco del "desengaño": en ellos sentimos, sobrecogedoramente, el ocaso de un temperamento dotado de sensual vitalidad.

El acto $V$ lleva a su culminación, antes de su fusión final, este entrelazamiento de percepciones líricas y cronológicas. Don Bela, antes tan confiado en que el desfile de amantes de Dorotea terminará en él, y suplantado ahora por otro, se consume de melancolía y busca en el idealismo neoplatónico un nuevo escudo contra el tiempo y el cambio. No da señales de menguar la incansable locuacidad con que los personajes tratan de alejar su consciencia del tiempo que huye. Pero en la escena quinta, cuando Dorotea quema los papeles que ha recibido de Fernando, reduciendo a cenizas los versos hechos para inmortalizarla, el tempo del diálogo se va intensificando y acelerando. Los pasajes que se detiene a leer se van haciendo más y más cortos, y Celia sufre cada vez con mayor impaciencia esa lectura. Las repetidas órdenes de Dorotea: "Vaya al fuego!", con el eco de la criada: "¡Vaya!", se van haciendo más y más premiosas, hasta que por último, cuando ya la bujía se acaba, los demás papeles son arrojados al fuego en montón. El compás cada vez más acelerado del diálogo subraya el derrumbamiento del mundo de Dorotea. En esta escena, magistral por su graduación lírica del ritmo, Dorotea se ve cogida en el incesante pulso del tiempo, al cual ha resistido hasta entonces. La acometida del tiempo físico vuelve a sentirse en sus frases entrecortadas del final: "La hermosura no buelue, la edad siempre passa, posada es nuestra vida, correo el tiempo, flor la juuentud. .." (fol. $267 \mathrm{v}^{\circ}$ ). Al concluir la acción en prosa, las vidas de todos los personajes -cada una a su manera- han quedado impregnadas de un sentido de "desen- 
gaño" que, en último análisis, es simplemente el de Lope proyectado en la experiencia individual y colectiva de sus creaturas. El omnipresente temple de ánimo del autor guía así los destinos individuales de los personajes. Por eso Vossler llamó a la Dorotea una "creación lírica teatral", y por eso nosotros hemos calificado de lírico su sentido de la fugacidad del tiempo.

Ahora, después de tres siglos y medio de progreso en la novela, tendemos a opinar que una forma narrativa flexible, como la que poco antes se había empleado en el Quijote, pudo haberle servido a Lope, mejor que un vehículo fundamentalmente dramático, para expresar el sentido de la vida desarrollándose en el tiempo. Pero Lope, hombre de su época, fue incapaz de apreciar lo hecho por Cervantes, y, además, demasiado bien conocía su propia falta de auténticas dotes narrativas ${ }^{3}$. Instintivamente se decidió por una forma dramática para la que consideraba su obra más ambiciosa y personal. Por otra parte, al desechar las restricciones del tablado, dejó despejado el campo para expresarse sin cortapisas. Pero el drama, por su misma naturaleza, cristaliza la acción en unos momentos bien seleccionados y no puede crear fácilmente la ilusión de un continuum temporal ni de un sereno proceso de cambio. Por eso, dentro de cada escena y dentro de cada acto, Lope acumula momentos en sucesión inin terrumpida, señalando cuidadosamente su marcha. Los intervalos entre acto y acto quedan cubiertos con relatos que el autor gradúa con minucia, y que poco a poco ponen de manifiesto los acontecimientos transcurridos mientras tanto. Así, pues, la excepcional forma de la "acción en prosa" puede verse como un fruto natural de la innata concepción dramática del mundo que Lope tenía, y del particular impulso lírico que lo guió en la Dorotea.

Alan S. Trueblood

Brown University.

\section{LA "CANCIÓN DESESPERADA" DE GRISÓSTOMO}

Don Américo Castro, de quien deben partir todas las indagaciones cervantinas -y muchas otras--, fue, según creo, el primero en interpretar la muerte del pastor-estudiante Grisóstomo como un caso de suicidio (hasta entonces, los lectores del Quijote, I, cap. 14, habian creído que Grisóstomo murió de amores)'․ La interpretación del egregio maestro me invita a volver sobre el tema, pues creo que este episodio nos deja vislumbrar aspectos poco explorados de la mente cervantina, tan problemática siempre.

s "Como cada escritor tiene su Genio particular a que se aplica, el mío no deue de ser éste", escribe Lope al comenzar su novela La prudente venganza, y añade que éste "es diferente estudio de mi natural inclinación" (La Circe, ed. facs. de la princeps de 1624, Madrid, 1935, fol. $\left.122 \mathrm{v}^{\circ}\right)$.

1 A. Castro, "Los prólogos al Quijote", RFH, 3 (1941), p. 337: "Del contexto de la prosa del Quijote en que se habla de la muerte de Grisóstomo, nadie saca la impresión de que el pastor obstinado se suicidó; eso es, sin embargo, lo que hizo y anuncia que va a hacer en la canción del capítulo 14, en donde dice que tomará una soga, se ahorcará, flotará su cuerpo al viento, no lo enterrarán en sagrado, irá al infierno, porque muere esin lauro o palma de futuros bienes»". 